\title{
Towards an Intelligent Multimodal Biometric Identification System
}

\author{
S. Akrouf, Member, IACSIT, A. Bouziane, A. Hacine. Gharbi, M. Mostefai and Y. Chahir
}

\begin{abstract}
- the goal of this project is to bring together and integrates the work of the laboratory team members in order to get a practical realization of an Intelligent Multimodal Biometric Identification System. This last exploits the vocal and visual properties of a person to carry out, her or his, identification. To improve classification performance, the system will have a virtual character module which can exchange information with the person to be identified according to a random survey (based on information provided previously). Our first objective is to equip our laboratory with a powerful access control system able to identify the members of the lab and follows them where ever they go helping them with all kind of information they may be in need to .
\end{abstract}

Index Terms-Biometric identification, Multimodal classification, Detection of movements, facial recognition, vocal Identification.

\section{INTRODUCTION}

Current Research in the field of biometric identification offers practical and effective solutions which make it possible to improve the performances of the traditional safety systems. These improvements are generally the fruit of the use of new sensors (of prints and Iris) powerful but constraining and expensive [1] [2].

In this work we propose the development of a nonconstraining biometric identification system which exploits the vocal and visual properties of a person to carry out his/her identification. In order to improve the classification performances, we propose to equip the system with a virtual character module which is able to exchange information with the person to be identified according to a random questionnaire (established using preliminary provided information).

\section{StATE OF THE ART}

Biometric identification techniques are based in general on the exploitation of certain physiological or behavioral characteristics of a person. These data resulting from biometric sensors form a unique signature which can be stored in a database for later identification. This primary stage is called enrollment phase [3] [4].When an enrolled person has to be identified, a reading and biometric process comparison is used. It consists in comparing the characteristics of the person to be identified with the characteristics recorded initially in of enrollment phase.

The biometric identification techniques can be classified in two great families: morphological techniques and behavioral

This work is part of a project number B03320090009* financed by the High Ministry of Education and Research techniques:

The first family is based on the identification of the physical and particular features of the person. It gathers the techniques based on the use of the fingerprints, the shape of the hand, the face, the retina and the eye iris.

The second family is based on the analysis of certain person behaviors such as for example a signature, the voice print or the way of carrying out certain specific tasks.

In general the powerful biometric identification systems combine several techniques resulting from the two families. It is the multimode approach [3].

In order to humanize the process of identification and to make it less constraining and more effective, we propose to associate to our system a virtual character module which is able to exchange information with the person to be identified according to a random questionnaire (established according to preliminary provided information).

In the next paragraph we will show the structure of our system and we will detail the developed modules.

\section{Structure of THE System Proposed}

The system suggested is composed of three principal modules:

The vocal identification module

The visual identification module

The virtual character module

The structure of the system is presented in figure 1 .

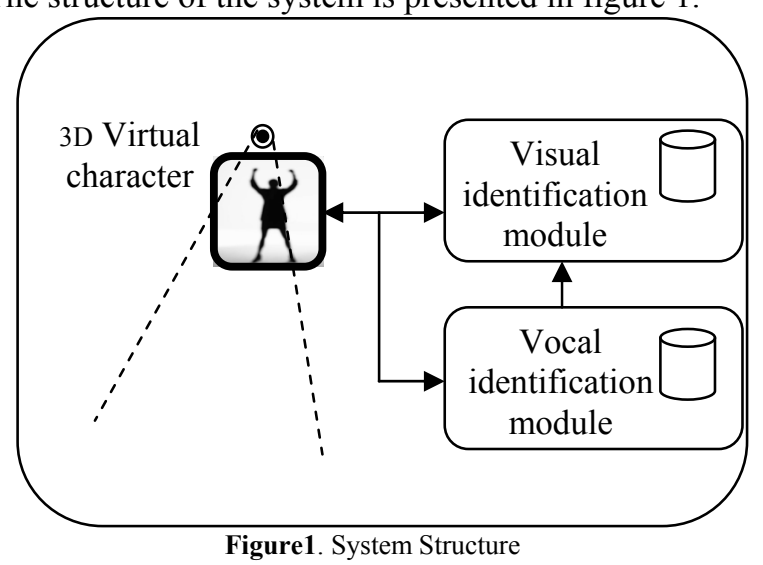

A) The vocal identification module: This module principal task is the speaker identification. First we acquire the speaker voice using a preliminary questionnaire and then, identify the voice by comparing it to the voices saved in the system database.

B) The visual identification module

This module exploits the results of the vocal identification in order to accelerate the process of visual identification based on the search for similarity between the acquired image 
and those which are in the image database.

C) Virtual character Module: this last module will enable us to work on new human machine interfaces which will be able to engage a series of messages resulting from external events.

\section{INTERACTION WITH ETERNAL ENVIRONMENT}

In order to make the system autonomous, a movement detector is used. Once a person enters the view field of the camera, the system starts the identification process by the following:

- Making a greeting by the virtual character, which asks the intruder to identify himself? An example of a message made by the virtual character is as follows: "Hello, What is your full name?"

- In parallel, the vocal and visual identification processes are switched on.

- When identified the person is allowed to enter and some information are kept in the data base concerning the person identified (such as the checking time etc...), otherwise it will be invited to leave. When in the lab, the person is followed and helped for what ever he needs.

\section{THE Vocal IDENTIFICATION MOdUle}

This module is based on two voice recognition systems:

1. A speaker recognition system allowing his/her identification [12].

2. A voice recognition system RAP associated with the virtual character module, allowing the confirmation of the identity of this speaker by a preliminary questionnaire as stated earlier. 1

The first system is to determine, among a set of $\mathrm{N}$ speakers, one corresponding voice recording.

Figure 2. illustrates this system.

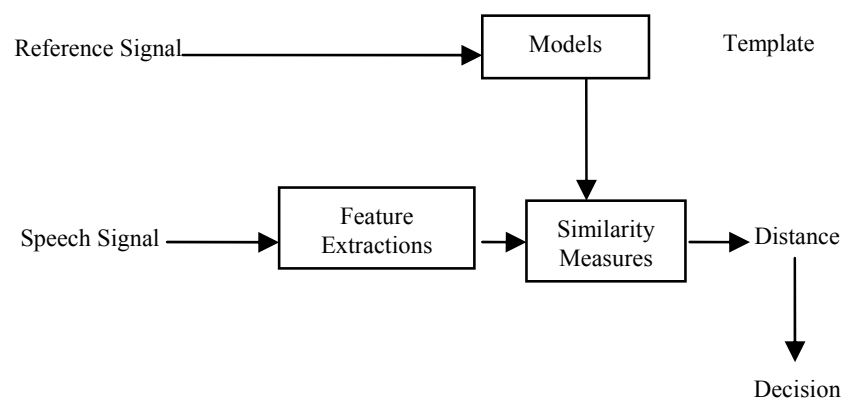

Figure 2.Speaker Recognition System

According to figure 3 , the voice presents major differences with the fingerprints [2].

This can be interpreted as follows:

The voice changes over time even in the short, medium and long-term, and depending on the health or emotional state.

The voice can be voluntarily modified (or imitated) and falsified, with the existing techniques.

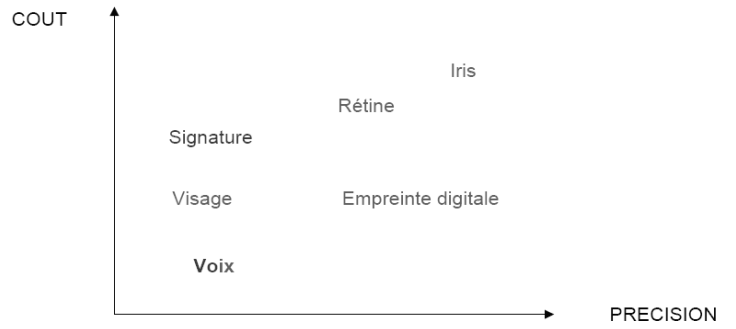

Figure 3. Comparison between various biometric techniques

In order to remedy this problem, the second system is conceived to ensure the proper identity of the speaker.

This system detects the human words and analyzes it in order to generate a string of words or phonemes representing the answers to the questionnaire of the virtual character, pronounced by the speaker.

Such system can be described according to the following axes [6]:

- Dependence or not of the speaker

- The mode of speech: isolated words or continuous speech.

- The complexity of the authorized language: size of the vocabulary and the difficulty of the grammar.

- The robustness to the conditions of recording: systems requiring high quality of speech or operating in noisy environment.

One of the ASR problems is the great variability of the characteristics of the word signal [6] [7]. To overcome this problem, many mathematical models and methods were developed, among which one can quote: the dynamic comparison, neurons networks, Markov stochastic models and in particular Markov hidden models HMM [8].

\section{Visual IDEnTIFICATION Module}

Before carrying out the visual identification of the intruder, the system carries out the localization of its face. For that several approaches were proposed to follow and locate the face.

According to Ahuja et al...In [4], four categories of approaches can be distinguished:

$>\quad$ Methods based on our intuitive representation of the face (presence of the mouth, the eyes and the nose).

$>$ Methods based on the features of the face which do not change, such as for example the color of the skin.

$>$ Methods based on a parametric representation of the face which constitutes a model (template matching).

$>\quad$ Methods based on appearance.

The process of visual identification is carried out in two stages: The first One locates the face then the other one identifies it.

\section{FACE LOCALISATION}

For this application we developed an operator of localization and follow-up of the face in real time based on the techniques of detection of movements [4].This last uses three successive images for the extraction of the movement in a video sequence. The mathematical expression of this 
operator is as follows:

$$
\begin{gathered}
\forall \mathrm{x}, \mathrm{y} \quad \mathrm{M}_{\mathrm{n}}(\mathrm{x}, \mathrm{y})=\max \left[\left(\left|C_{\mathrm{n}}(\mathrm{x}, \mathrm{y})-C_{\mathrm{n}-1}(\mathrm{x}, \mathrm{y})\right|\right),\right. \\
\left.\left(\left|C_{\mathrm{n}}(\mathrm{x}, \mathrm{y})-C_{\mathrm{n}+1}(\mathrm{x}, \mathrm{y})\right|\right)\right]
\end{gathered}
$$

With $C n_{-1}, C n$ and $C n_{+1}$ are the respective contours of the successive images $I n_{-1}$, and ${ }_{+1}$.

The operator proposed allows detecting the least movement in the filmed scene and gives a null result only if the scene is static.

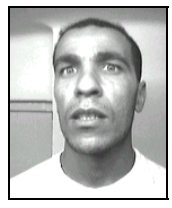

$I_{n-1}$

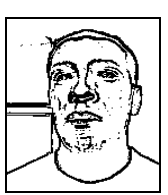

$C_{n-1}$

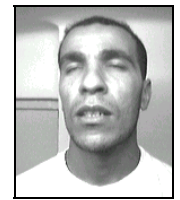

$I_{n}$

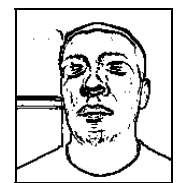

$C_{n}$

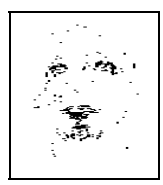

Figure 4. Obtained Result by the proposed Operator

It is significant to note that the request stage of the intruder identity by the virtual character will oblige the person to identify to mainly move his lips and his eyes. This will enable us to carry out a good localization and extraction of the face. Once the face extracted we pass to the recognition phase.

\section{FACE IDENTIFICATION}

After detection and standardization, the faces are normally forwarded to an algorithm of recognition. We used a hybrid method [11] combining two global methods PCA [9] and DCT [10]. Figure 5 presents the stages of an algorithm of recognition. A data base of images, BBAFaces figure 6, was created at the university center of Bordj-Bou-Arréridj in order to test the performances of the developed system.

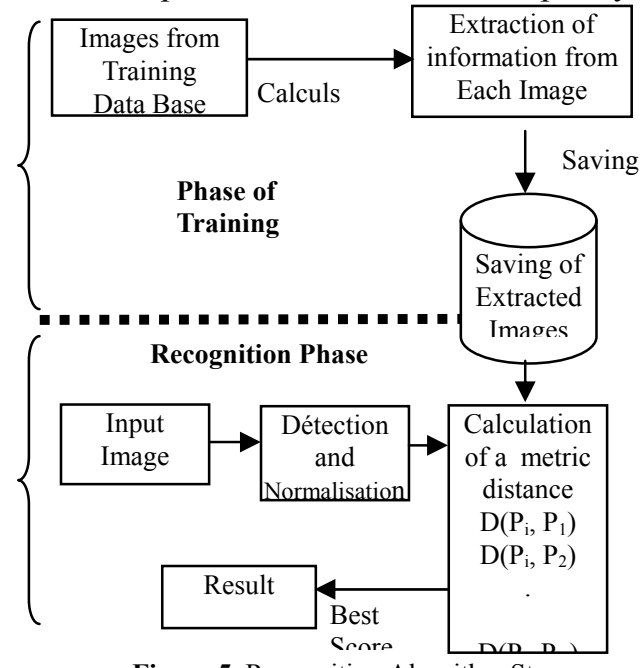

Figure 5. Recognition Algorithm Stages
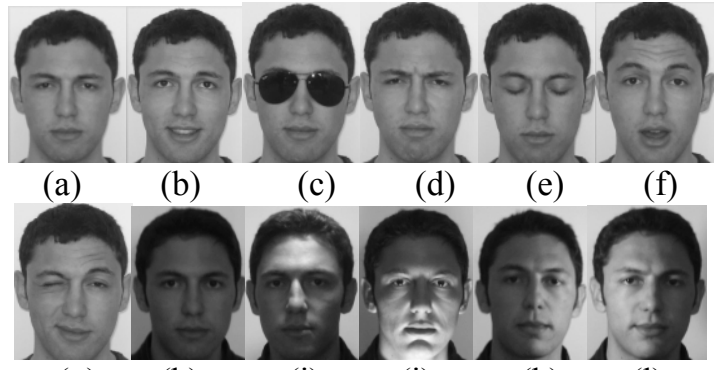

(g) (h)

(i)

(j)

(k)

(1)

Figure 6. : BBAFaces Database Example (a): normal, (b): happy, (c): glasses, (d): sad, (e): sleepy, (f): surprised, (g): wink, (h): dark, (i): top light, (j): bottom light, (k): left light, (l): right light.

The combined use of PCA and DCT is nothing but the transformation of each image (for training and for recognition) via DCT method before using it as input for the PCA. This technique, although needing more calculation time-consuming, offers a higher recognition rate than PCA or DCT method used alone. Its other advantage is that it consumes less memory space than PCA.

\section{CONCLUSION}

In this project we have set a common goal to bring together the work of our team members on a practical application in the field of biometric identification. Besides the virtual character module, the main components of the systems which include: visual and voice identifying were developed. The proposal of a random survey will enable us to increase the system performances. It remains to combine the methods and work on the interactive side of the system with the external environment

\section{REFERENCES}

[1] A. K. Jain, A. Ross et S. Pankanti, "Biometrics: A Tool for Information Security," IEEE Trans. on Information Forensics and Security, 1: 2, 125-143, 2006.

[2] L. Hong and A. Jain, "Integrating Faces and Fingerprints for Personal Identification", IEEE Transactions on Pattern Analysis and Machine Intelligence, vol. 20, no. 12, pp. 1295-1307, 1998.

[3] A. K. Jain, R. Bolle et S. Pankanti, "Introduction to Biometrics," : Personal Identification in Networked Society, Kluwer Academic Publishers, 1999.

[4] D. Mechta 'Localisation et suivi des traits caractéristiques du visage dans une scène naturelle", mémoire magister informatique, université de sétif, juin 2004

[5] A. Drygajlo, 'TRAITEMENT DE LA PAROLE', IDIAP, Martigny, Lausanne 2003, http://scgwww.epfl.ch/courses.

[6] J.P.Halton, J.M.Pierrel, G.Perennou, J.Caelen et J.L.Gauvanin, 'reconnaissance Automatique de la parole ', Bordas, Paris, 1991.

[7] H.BOULAR, “ Introduction à la reconnaissance de la parole et du locuteur ", IDIAP- RR 98-13.

[8] L.R.Rabiner, B.H.Juang, 'Fundamentals of speech recognition' Prentice Hall, New Jersey, 1993

[9] M. Turk and A. Pentland. Eigenfaces for recognition.Journal of Cognitive Science, pages 71-86, 1991.

[10] Ronny Tjahyadi, Wanquan Liu, Svetha Venkatesh. Application of the DCT Energy Histogram for Face Recognition. 2nd International Conference on Information Technology for Application (ICITA 2004) PP 305-310

[11] Face Recognition Using PCT and DCT Akrouf Samir, Sehili Mohamed El Amine, Chakhchoukh Abdesslam, Youssef 
Chahir and Messaoud Mostefai 2009 the 5th International Conference on Mems Nano and Smart Systems (ICMENS 2009)' Dubai 28-30 December 2009 (www.ijcee.org/icmens)

[12] An Automatic Speaker Recognition System, 2009 the $2^{\text {nd }}$ International Conference on Advanced Computer Theory Engineering (ICACTE 2009) Cairo, Egypt September 25-27 2009 Akrouf Samir, Mehamel Abbas, Benhamouda Nacéra, Messaoud Mostefai (www.icacte.org)

Samir Akrouf was born in Bordj Bou Arréridj, Algeria in 1960. He received his Engineer degree from Constantine University, Algeria in 1984 . He received his Master's degree from University of Minnesota, USA in 1988. Currently; he is an assistant professor at the Computer department of Bordj Bou Arréridj University, Algeria. He is an IACSIT member and is a member of LMSE laboratory (a research laboratory in Bordj Bou Arréridj University). Currently he is an assistant professor at Bordj Bou Arréridj University and he is also the director of Mathematics and Computer Science Institute of Bordj Bou Arréridj University. His main research interests are focused on Biometric Identification, Computer Vision and Computer Networks.

Abderraouf Bouziane was born in Bordj Bou Arréridj, Algeria in 1976. He received his Engineer degree from Setif University, Algeria in 2000 . He received his Magister degree from Setif University, Algeria in 2003. Currently he is a PhD Student in the department of Computer Science at Caen
University France. His main research interests are focused on classification and Biometric Identification Systems.

Abdennour Hacine Gharbi was born in El Eulma, Algeria in 1972. He received his Engineer and Magister degree from Setif University, Algeria respectively in 1995 and 2002. Currently; he is a PhD Student at the electronics department of Setif University, Algeria. His main research interests are focused on classification and speech recognition.

Messaoud Modtefai was born in Bordj Bou Arréridj, Algeria in 1967. He received his Engineer degree from Algiers University, Algeria in 1990. He received a DEA degree en Automatique et Traitement Numérique du Signal (Reims - France) in 1992. He received his doctorate degree en Automatique et Traitement Numérique du Signal (Reims - France) in 1995. He got his HDR Habilitation Universitaire: Theme: "Adéquation Algorithme /Architecture en traitement d'images » in (UFAS Algeria) in 2006. Currently; he is a professor at the Computer department of Bordj Bou Arréridj University, Algeria. He is a member of LMSE laboratory (a research laboratory in Bordj Bou Arréridj University). Currently he is an assistant professor at Bordj Bou Arréridj University. His main research interests are focused on classification and Biometric Identification, Computer Vision and Computer Networks.

Youssef Chahir Associate Professor (since '00) at GREYC Laboratory CNRS UMR 6072, Department of Computer Science, University of Caen Lower-Normandy France. 